[Espaço pedagógico]

\title{
ALGUMAS CONSIDERAÇÕES DIDÁTICO-PEDAGÓGICAS SOBRE O ENSINO REMOTO
}

Profa. Dra. Rosária Helena Ruiz Nakashimai

RESUMO: Neste white paper ${ }^{1}$ (GRAHAM, 2013) serão apresentadas algumas reflexões e sugestões para o planejamento e o desenvolvimento de atividades didáticopedagógicas remotas, no ensino superior.

A versão mais atualizada deste artigo está disponível em https://osf.io/uzn69/download

\section{Como ser coautor (a) deste artigo?}

a) Envie-nos suas observações e responda às seguintes perguntas.

b) Quais discussões você adicionaria a este artigo?

c) Você encontrou algum erro ou argumento inconsistente? Dê uma justificativa detalhada.

\section{ENSINO REMOTO}

1. "[...] o ensino remoto comporta potencialidades e desafios, que envolvem pessoas, tecnologias, expertise e infraestrutura" (GARCIA et. al, 2020, p. 5).

2. Não se trata de fazer apenas uma transposição da aula presencial para o modelo remoto.

3. "Ensinar remotamente não é sinônimo de ensinar a distância, embora esteja diretamente relacionado ao uso de tecnologia e, nesse caso, digital" (GARCIA et. al, 2020, p. 5). 
4. "Ensinar remotamente permite o compartilhamento de conteúdos escolares em aulas organizadas em plataformas de ensino" (GARCIA et. al, 2020, p. 5), como Moodle, Google Classroom etc.

5. Os recursos whatsapp, Google Meet, lives no Instagram e YouTube também podem ser utilizados para apoiar o desenvolvimento do ensino remoto.

6. "A variabilidade dos recursos e das estratégias, bem como das práticas é definida a partir da familiaridade e da habilidade do professor em adotar tais recursos" (GARCIA et. al, 2020, p. 5).

7. A "comunicação com o aluno poderá ser síncrona (em tempo real) ou assíncrona (em tempo diferente), assim como na sala de aula convencional" (GARCIA et. al, 2020, p. 9).

\section{PLANEJAMENTO DIDÁTICO-PEDAGÓGICO}

8. Assim como no presencial, o planejamento da aula é fundamental no ensino remoto.

9. "A primeira etapa de um planejamento didático é o conhecimento da realidade e isto inclui o ambiente escolar e comunitário, as aspirações, as frustrações, as necessidades e as possibilidades dos alunos" (CONSOLARO, 2005, p. 73).

10. Lembrar-se que há discentes com problemas de acessibilidade tecnológica e que $\mathrm{o}$ ambiente social e emocional onde eles se encontram pode trazer fragilidades para a aprendizagem.

11. Neste contexto de pandemia, é importante ter sensibilidade e acolhimento (NAKASHIMA, 2020a) diante das situações discentes, principalmente os mais vulneráveis socialmente.

12. No ensino remoto, um roteiro para a realização de estudos dirigidos é um importante instrumento de apoio didático-pedagógico, contendo as informações dos itens a seguir, bem como a descrição das atividades a serem realizadas. 
a. "Apresentar o conteúdo: indicação e disponibilização do assunto a ser abordado na aula, de forma clara e objetiva, podendo ser a adotada a metodologia de tópicos seguidos de orações curtas descrevendo o assunto" (GARCIA et. al, 2020, p. 6).

b. "Definir objetivos da aprendizagem: indicação, seguida de descrição de quais os conhecimentos, habilidades e atitudes o aluno deverá desenvolver como resultado da aprendizagem" (GARCIA et. al, 2020, p. 6).

c. "Propor atividades de avaliação: definição, informação e esclarecimentos aos alunos quanto as formas e métodos de acompanhamento da aprendizagem" (GARCIA et. al, 2020, p. 7).

13. A Diretoria de Avalição e Desenvolvimento de Ensino da Universidade Federal de Lavras elaborou um modelo de Roteiro de Estudos Orientados (REO) e disponibilizou em sua página: http://dade.ufla.br/destaques/estudoemergencial-remoto.

\section{DIMENSIONAMENTO DO TEMPO}

14. A dinâmica das aulas realizadas remotamente é muito diferente dos encontros presenciais e exige o planejamento de atividades equilibradas e bem distribuídas. Por se tratar de uma situação excepcional, sugere-se:

a. "Selecionar, no plano de ensino, as unidades e conteúdos fundamentais para a formação do estudante, a fim de evitar a sobrecarga de atividades" (DUARTE et. al, 2020, p. 7).

b. "Alterar o conceito de aula, como hora-aula correspondente ao encontro presencial, para uma sequência articulada de ensino, envolvendo atividades síncronas e assíncronas integradas aos objetivos de aprendizagem definidos" (DUARTE et. al, 2020, p. 7).

c. "O planejamento da disciplina deve considerar que o aluno realize todas as atividades (encontro síncrono, leituras, videoaulas, resenhas, estudo 
dirigido etc.) no tempo semanal reservado para a disciplina". (DUARTE et. al, 2020, p. 11). Exemplo: em uma disciplina de 2 créditos/30 h todo conteúdo relativo a esta precisa ser planejado para ser desenvolvido em $2 \mathrm{~h}$ semanais.

d. Quando for o caso, "realizar as atividades síncronas no mesmo horário previsto na oferta da atividade acadêmica curricular, devendo graválas e disponibilizá-las aos estudantes matriculados na turma correspondente" (DUARTE et. al, 2020, p. 8).

e. "Priorizar atividades assíncronas, possibilitando mais flexibilidade de tempo e espaço para o estudo, com o objetivo de garantir efetividade de conexão, comunicação e aprendizagem" (DUARTE et. al, 2020, p. 8).

f. Definir atividades assíncronas com uma diversidade de formatos (fóruns de discussão, elaboração de resumos, parágrafo-padrão, mural ou mapa conceitual, produção de vídeo ou podcast etc.), "buscando favorecer interações individuais e coletivas. Tais atividades devem ser planejadas em função dos objetivos de aprendizagens e dando sentido a uma sequência de ensino, para não serem reduzidas ao comportamento de cumprimento de tarefas com fim em si mesmas" (DUARTE et. al, 2020, p. 8).

g. Planejar $\bigcirc$ uso dos ambientes virtuais de aprendizagem, numa perspectiva inclusiva, com "atividades e recursos didáticos para os estudos, considerando a inclusão de pessoas com deficiência e as condições de estudos dos alunos no contexto de pandemia, que exige flexibilidade de tempo por meio de acesso às atividades síncronas e assíncronas [...]" (DUARTE et. al, 2020, p. 8).

15. "O excesso de atividades síncronas decorrentes de diversas atividades acadêmicas curriculares cursadas pelo estudante piora o desempenho acadêmico" (DUARTE et. al, 2020, p. 10). 
16. "Recomenda-se que as aulas expositivas na modalidade síncrona tenham duração de até 20 minutos e, estabelecendo diálogo, até no máximo 50 minutos para favorecer a atenção" (DUARTE et. al, 2020, p. 11).

17. Priorizar o espaço síncrono para discussão e esclarecimento de dúvidas.

\section{AVALIAÇÃO DA APRENDIZAGEM}

18. Recomenda-se "[...] a adoção de práticas avaliativas baseadas na reflexão, construção, criatividade, parceria, autoavaliação e autonomia, princípios que se referem tanto ao trabalho do aluno como ao do professor" (DUARTE et. al, 2020, p. 14).

19. "Essa postura pedagógica e avaliativa pode conduzir à substituição da concepção de que o aluno vem à universidade para 'assistir à aula' pela concepção de que ele desenvolve um trabalho que the pertence, isto é, de cuja formulação, execução e avaliação ele participa" (DUARTE et. al, 2020, p. 14).

20. "A avaliação ganha outro sentido porque o estudante passa a ser produtor da sua aprendizagem. Isso requer mudanças não apenas na avaliação, mas na organização do trabalho pedagógico na universidade, nos cursos, nas disciplinas e nas atividades propostas" (DUARTE et. al, 2020, p. 14).

21. Este pode ser um importante momento para a construção de uma pedagogia universitária mais significativa, inclusiva e pertinente (NAKASHIMA; LOBO, 2020, p. 1).

22. É importante diversificar os instrumentos de avaliação, prevendo atividades capazes de coletar dados sobre a aprendizagem da turma no processo, ou seja, durante o desenvolvimento da disciplina e não somente ao final ou em momentos pontuais.

23. Buscar o equilíbrio, evitando "a pontuação excessiva de uma única atividade ou, por outro lado, o excesso de atividades pontuadas" (DUARTE et. al, 2020, p. 8).

24. Também é interessante planejar atividades avaliativas individuais e em grupo. 
25. "Construir propostas que viabilizem novos modos de avaliar a aprendizagem, assumindo que avaliar é construir caminhos que favoreçam o acompanhamento das aprendizagens, identificando avanços e desafios" (DUARTE et. al, 2020, p. 8).

26. "A avaliação é a parceira do professor, revelando-lhe se o estudante, que fora ensinado, aprendera, ou não, os conteúdos e habilidades trabalhados" (LUCKESI, 2018, p. 145).

27. "[...] a avaliação é o recurso que the oferece notícias da qualidade da aprendizagem por parte do estudante, fator que the garante a possibilidade de tomada de decisões, seja para assumir como encerrada uma atividade de ensino, desde que já atingira sua meta, seja para decidir por novos investimentos, desde que o resultado desejado ainda não tenha sido atingido" (LUCKESI, 2018, p. 145).

28. Os critérios de avaliação devem ser planejados e evidentes para docentes e discentes.

29. A revelação da qualidade da avaliação se dá através da comparação da realidade descrita (respostas/aprendizado da turma), por meio instrumentos de avaliação, com os parâmetros de qualidade assumidos como válidos (critérios de avaliação previamente estabelecidos).

\section{ALGUNS RECURSOS DIGITAIS INTERESSANTES}

30. Google Classroom é um sistema de gerenciamento de conteúdo para escolas que procuram simplificar a criação, a distribuição e a avaliação de trabalhos. Tutorial: $\quad$ https://ceduc.unifei.edu.br/tutoriais/google-classroom-criacao-deturmal

31. O Google Forms é um serviço gratuito para criar formulários online. Nele, o usuário pode produzir pesquisas de múltipla escolha, fazer questões discursivas, solicitar avaliações em escala numérica, entre outras opções. A ferramenta é ideal para quem precisa solicitar feedback sobre algo, organizar inscrições 
para eventos, convites ou pedir avaliações. Tutorial: https://ceduc.unifei.edu.br/tutoriais/google-forms-criando-um-teste/

32. O Jamboard é um quadro interativo desenvolvido pelo Google, como parte da família G Suite. Tutorial: https://ceduc.unifei.edu.br/tutoriais/como-utilizar-aplataforma-jamboard/

33. O Miro oferece múltiplas oportunidades, ao contrário da parede de uma sala, sempre permite preparar o quadro previamente e irmos expandindo na medida em que evoluímos. Tutorial: https://ceduc.unifei.edu.br/tutoriais/comoutilizar-a-plataforma-miro/

34. Kahoot! é uma plataforma de aprendizado baseada em testes de múltipla escolha. Tutorial: https://ceduc.unifei.edu.br/tutoriais/como-utilizar-aplataforma-kahoot/

\section{REFERÊNCIAS}

CONSOLARO, Alberto. O "ser" professor: arte e ciência no ensinar e aprender. 4. ed. Maringá: Dental Press, 2005.

DUARTE, Ricardo de Oliveira et. al. Ensino Remoto Emergencial (ERE) nos cursos de graduação da UFMG. Minas Gerais: Centro de Apoio ao Ensino a Distância - CAED, 2020.

GARCIA, Tânia Cristina Meira et. al. Ensino remoto emergencial: proposta de design para organização de aulas. Natal: SEDIS/UFRN, 2020.

GRAHAM, Gordon. White Papers for Dummies. New York: Wiley, 2013.

LUCKESI, Cipriano Carlos. Avaliação em educação: questões epistemológicas e práticas. São Paulo: Cortez, 2018.

NAKASHIMA, R. H. R.; LOBO, M. P. "Virada curricular": por uma pedagogia universitária relevante, equitativa e solidária. 2020. Participativa: Ciência Aberta em Revista. Disponível em:

https://revistaparticipativa.wordpress.com/2020/09/03/virada-curricular-por-umapedagogia-universitaria-relevante-equitativa-e-solidaria/. Acesso em 23 set. 2020.

NAKASHIMA, R. H. R. Proposta de ensino remoto intencional: alguns passos para um recomeço. Participativa: Ciência Aberta em Revista. Disponível em:

https://revistaparticipativa.wordpress.com/2020/09/24/proposta-de-ensino-remotointencional-alguns-passos-para-um-recomeco/. Acesso em 23 set. 2020. 
i Doutora na área de Didática, Teorias de Ensino e Práticas Escolares, pela Faculdade de Educação da Universidade de São Paulo (USP). Professora Adjunta do Curso de Licenciatura de História da Universidade Federal do Tocantins (UFT), Campus de Araguaína-TO. Docente do Programa de PósGraduação em Estudos de Cultura e Território - PPGCult (UFT). E-mail: rosaria@uft.edu.br 